\title{
Optimising Storage Resource using Morpheme based Text Compression Technique
}

\author{
Rockson Kwasi Afriyie \\ Department of Computer \\ Science \\ Kwame Nkrumah University of
}

Science and Technology,

Ghana

\author{
J. B. Hayfron-acquah \\ Department of Computer \\ Science Kwame Nkrumah \\ University of Scienceand
}

Technology, Ghana

\author{
Joseph K. Panford \\ Dpt. of Computer Science \\ KNUST, Ghana
}

\begin{abstract}
In this paper, we present a text compression technique which utilises morpheme-based text compression to optimise storage resources. The proposed technique is designed to decompose words into their morphemes and then to produce code representations for compression. The proposed algorithm is implemented using English Language text data and applied using 30 different texts of different lengths collected from different sources with different natures. The efficiency increases with the increase in the number of long, repetitive morphemes in the input data. To the best of our knowledge, the resulting implementation is the first to demonstrate lossless compression using such a technique. We illustrate its suitability and effectiveness on a number of benchmark file sizes - small, middle-sized, large, and very large real-world application. The results indicated a good compression performance of $98 \%$ making the approach an attractive one. A further virtue of this method is its dynamic application. A degraded compression can be compensated for by appending identified morphemes within the document to the dictionary to improve compression. The evaluation experiments show that: if storage space is the primary consideration, the morphemebased text compression technique is an efficient approach for compressing text data.
\end{abstract}

\section{General Terms}

Text compression: Morpheme

\section{Keywords}

Algorithm, morpheme, clean data, storage resource

\section{INTRODUCTION}

The demand and dependence on digital data and information keep on increasing. New knowledge, ideas and technologies are created and added daily into the annals of organisations, institutions, governments, and even individuals; their daily digital data and document files needs keep on growing to significant sizes. It is asserted that "The web is creating massive amounts of data every second of the day [15]. Moore's law states that the amount of digital information increases tenfold every five years and the Social Web is accelerating data" [15]. A special report in The Economist, Andrew Brust [2] observed that we are at the point of an "industrial revolution of data," with vast amounts of digital information being created, stored and analysed. The rise of "big data" has led in turn to an increased demand for tools to both visualise and analyse the information. The New Competition Is Data; Data Complications" [15]. The information in schools, offices, libraries, books, etc is mostly textual data which keeps on increasing daily. Projects such Gutenberg, Distributed Proofreaders and Digital Text Community are converting already published books into eBooks $[5,17]$. They are electronically preserving the literary material and other media of the world for everyone to use [5] Digital Text Community is digitising "ink-on-paper" text such as books, periodicals, documents [8] and most hitherto physical libraries are also being digitised. The arrival of total digitised education or world would surely be the beginning of data storage trauma. This will be the time and period when every learnable and learnt material in schools, colleges and universities can only be accessed electronically.

\subsection{Theory of Data Compression}

The theoretical background of compression is provided by information theory. Information theory is a study of information based on probability theory [7]. It was proposed by Claude E. Shannon at Bell Laboratories in 1948 [12] and based on people's reception and reaction towards given information; which is aimed at a mathematical way of measuring the quantity of information [7]. Data compression is the fundamental expression of information theory which is a branch of mathematics concerned with various questions about information, including different ways of storing and communicating messages [12]. Data compression is connected to the field of information theory because of its concern with redundancy [12]. Redundancy is the number of bits used to transmit a message minus the number of bits of actual information in the message. According to Wikipedia, redundancy refers to "the amount of wasted "space" used to transmit certain data" [17]. Data compression is a way to reduce or eliminate unwanted redundancy. Therefore, the basis of any data compression algorithm depends on the presence of redundancy in the given data. The more redundancy the source data has, the more effective a compression algorithm may be [7].

\subsection{Early Development in Data Compression}

According to history of irreversible data compression, the idea of creating sounds by adding together pure tones goes back to antiquity [18]. Following work by Joseph Fourier around 1810 , it became clear by the mid-1800s how smooth function could be decomposed into sums of sine waves with frequencies corresponding to successive integers. Early telephony and sound recording in the late 1800s already used the idea of compressing sounds by dropping high-and lowfrequency components [18]. Early days of television in the 
1950s saw similar kinds of compression for images but serious efforts were made when digital storage and processing of images became common in the late 1980s [18]. Morse code used in telegraphy was a form of earliest text compression [18]. Modern data compression began in 1940s with the development of information theory [18]. In 1949, Claude Shannon and Robert Fano introduced the method of compressing information using probabilities of blocks and in late 1970s, software compression programs based on adaptive Huffman coding were developed [18]. In 1977, Abraham Lempel and Jacob Ziv published a paper with a different approach to the symbol coding problem; their method is the basis of most lossless data compression techniques [11, 18]. The late 1980s and early 1990s saw digital images compression standards and lossy compression methods respectively [18].

\subsection{Data Compression Algorithms}

A data compression algorithm refers to the step-by-step methodologies employed to compress data into a relatively small size with the aim of converting source data at the compression end into a compressed message [7] and restore it precisely the same content information or with little distortion. Compression algorithms can be divided into two major families [12]. They are lossless compression and lossy compression [11, 13]. The lossless compression which is applied to database records, spreadsheets, or word processing files, encodes the original input without loss of information. The lossy compression accepts a slight loss of data and proves effective when applied to graphics, images and digitised voice [12]. An algorithm may be static or adaptive Figure 1 and Figure 2 respectively base on its ability to adjust itself. The compression algorithm which samples from the inputs to adjust the model is called adaptive compression [13]. A fixed model compression algorithm is called static modelling compression.

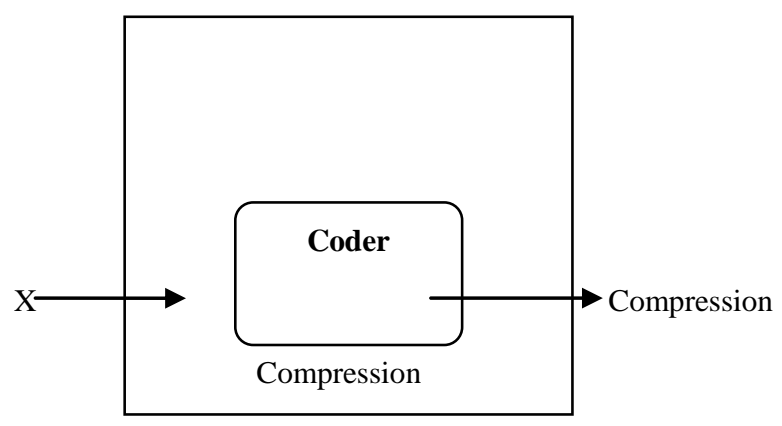

Figure 1: Static compression model diagram

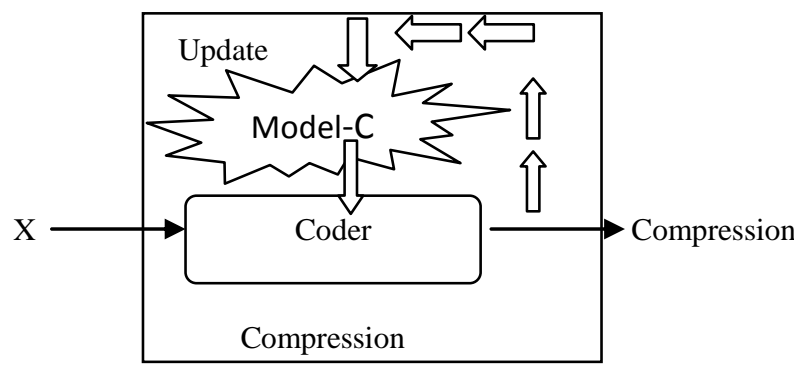

Figure 2: Adaptive compression model diagram

\subsection{Characteristics of Existing Compression Algorithms}

There are two major ways to compress data, Statistical-based model and Dictionary-based model [6]. The choice of either method is informed by the type of data being compressed. The statistical-based algorithms explore the numerical redundancy of individual characters within the data.

\subsection{Statistical-Based Compression Method}

The statistical-based algorithms explore the numerical redundancy of individual characters within the data. It is based on counting individual symbol and the determination of its frequency of occurrence. This technique achieves compression by assigning shorter codes to most frequently used symbols and longer codes to rare appeared symbols [14] Among the compression techniques that use statistical criterion are Huffman coding algorithm, Shannon-Fano algorithm, run-length coding and arithmetic algorithms [7].

\subsection{Dictionary-Based Data Compression}

A dictionary-based compression scheme uses a different concept [12]. A coding system (coder) keeps a pattern of characters in memory called dictionary, which keeps string patterns seen before and the indices are used to encode the repeated patterns [7]. It reads in input data and looks for groups of symbols that appear in a dictionary. If a string match is found, a pointer or index into the dictionary is output instead of the code for the symbol. When the match is longer, the compression ratio is better, however, the size of the dictionary may affect the efficiency of the algorithm. In general, dictionary-based compression replaces phrases (symbols) with pointers. If the number of bits in the pointer is less than the number of bits in the phrase, compression will occur. However, the methods for building and maintaining a dictionary are varied. Some popular dictionary-based algorithms are LZ77 and LZ78 compression algorithms.

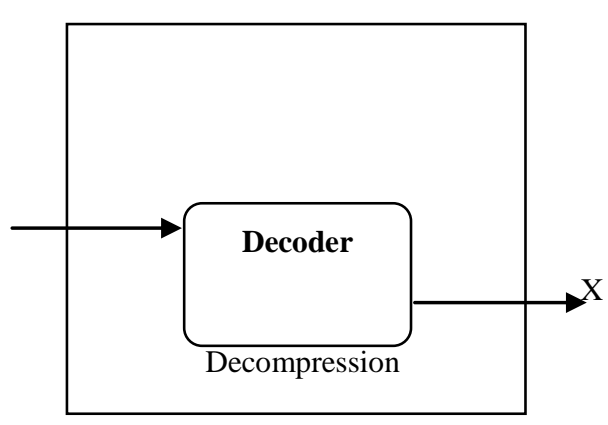




\subsection{Recent Development in Data Compression}

Data compression as an area for research work is generally not new. According to Ibrahim Akman and his colleagues, most text compression algorithms perform compression at character level or at word level [1]. Jan Lansky and Michal Zemlicka reported that there are two basic types of text compression by symbol representation - the characters and words. They believe that, the syllable is another way by which text can be compressed [9]. They claimed that syllable, character and word compressions will be suitable for middle, small and very large files respectively. Today's advances in lossless file compression, generally assume that there is an inherent redundancy in text and therefore seek to minimise or eliminate these redundancies [7]. Most text compression algorithms perform data compression at character level or word level and they do not consider adjacent string structures in words such as syllable [1]. The existing text compression techniques have been reported to have some weaknesses [1]. At the character level, a single bit error may be sufficient to result in a long stream of errors in the coded file, at the syllable level, the compression ratio does not meet the desired storage requirements and the most effective compression algorithms are reported to be computationally expensive [1]

\subsection{Overview of Morpheme Concept}

A morpheme is the smallest bit of language that has its own meaning; either a word or a part of a word [3]. Every language has a morpheme and every word comprises one or more morphemes. They can be classified in different ways. A morpheme may be free or bound [10]. Free morphemes can stand alone and function independently as words; while bound morphemes appear only together with other morphemes or as parts of words, always in conjunction with a root. Bound morphemes can be split further into derivational or inflectional $[5,10]$. Derivational morphemes are the type, whose part of speech is modified upon root combination. For instance, in the word joyfulness, the addition of the bound morpheme -ness to the root joyful changes the word from an adjective (joyful) to a noun (joyfulness). Inflectional morphemes cause a change to a noun's number or verb's tense leaving the word's meaning or class intact. They are achieved by addition of $-s$ or $-e d$ to the root. For example, adding $-s$ to the root $d o g$ to form $\operatorname{dog} s$ and adding ed to wait to form waited. English has eight inflectional affixes - affixes that depend on the function of a word in a sentence. For example, the inflectional affix's' on the end of pot makes the word plural. The remaining affixes in English are derivational affixes, which change the form or meaning of words. Table 1 lists all eight of the inflectional affixes in English.
Table 1: The inflectional affixes in English Language

\begin{tabular}{|l|l|l|l|l|}
\hline Inflectional Affixes & \multicolumn{3}{|c|}{ Derivational Affixes } \\
\hline $\begin{array}{l}\text { S: creates plural } \\
\text { nouns }\end{array}$ & Noun & Verbs & Adjective & Adverb \\
\hline $\begin{array}{l}\text { S: creates possessive } \\
\text { nouns }\end{array}$ & -ant & -ate & -able & -ly \\
\hline $\begin{array}{l}\text { S: creates third } \\
\text { person singular } \\
\text { verbs }\end{array}$ & -er & -en & -al & -ward \\
\hline $\begin{array}{l}\text { Ed: creates verbs } \\
\text { past tense }\end{array}$ & -hood & -ise & -ful & -wise \\
\hline $\begin{array}{l}\text { en: creates past } \\
\text { participle }\end{array}$ & -ment & others & -y & others \\
\hline $\begin{array}{l}\text { ing: creates present } \\
\text { participle }\end{array}$ & -ness & & -ous & \\
\hline $\begin{array}{l}\text { er: creates } \\
\text { comparatives }\end{array}$ & -tion & & others & \\
\hline $\begin{array}{l}\text { est: creates } \\
\text { superlatives }\end{array}$ & others & & & \\
\hline
\end{tabular}

Table 2 labels the various morphemes in a typical English sentence: "The students have a wonderful teacher"

Table 2 : Illustration of morphemes

\begin{tabular}{|l|l|l|l|l|l|l|l|l|}
\hline The & $\begin{array}{l}\text { stud } \\
\text { ent }\end{array}$ & $\mathrm{s}$ & $\begin{array}{l}\text { hav } \\
\mathrm{e}\end{array}$ & $\mathrm{a}$ & $\begin{array}{l}\text { won } \\
\text { der }\end{array}$ & ful & $\begin{array}{l}\text { teac } \\
\mathrm{h}\end{array}$ & er \\
\hline free & free & bound & free & free & free & $\begin{array}{l}\text { boun } \\
\mathrm{d}\end{array}$ & free & $\begin{array}{l}\text { boun } \\
\mathrm{d}\end{array}$ \\
\hline
\end{tabular}

\section{MATERIALS AND METHODS}

\subsection{Research Design}

Experimental research design was used to obtain information about the population by selecting and experimenting sample from the entire population. Scientific sampling procedure was used to select 30 text data files from different sources of different natures for the implementation and experimentation of the proposed algorithm.

\subsection{The Proposed Algorithm}

The proposed morpheme-based algorithm works using English text data as follows:

Miss - "Mis" and "s"; Rejoyce - "Re", "joy" and "ce", displays - "dis", "play" and "s" etc.

The proposed algorithm is as follows:

i. Read the text input

ii. Partition the string input into possible morphemes

iii. Extract morphemes.

iv. Scanned the extracted morpheme through the dictionary to do a match if there exist.

v. Represent the morphemes with the relevant code representation

vi. If the string in the input text is not in the morpheme unit passed text unaltered.

The operation of the algorithm is further illustrated in Figure 3 using a flow chart. 


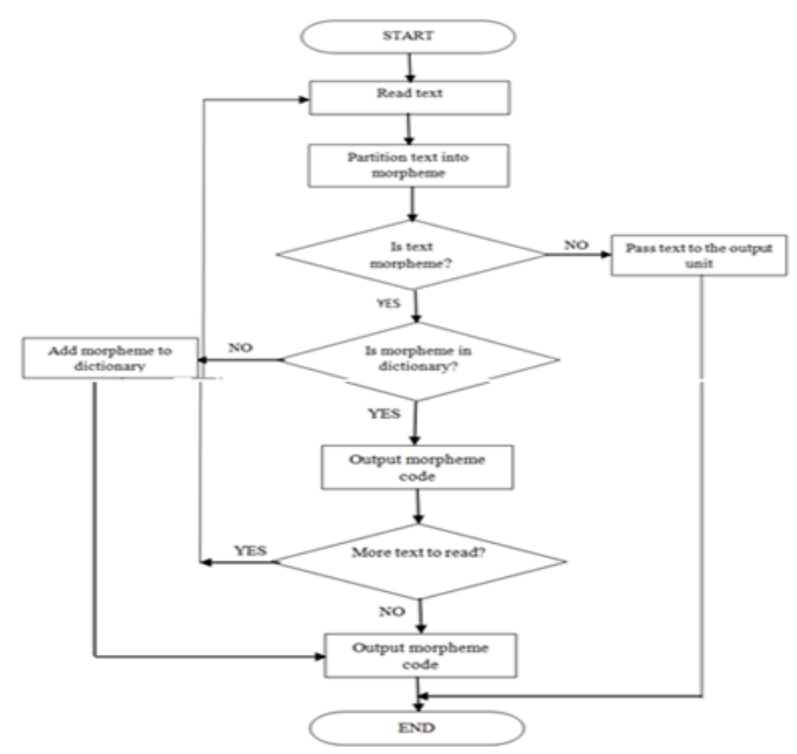

Figure 3: Morpheme-based text compression algorithm flowchart

Table 3: Alphabets Number Assignment

\begin{tabular}{|cc|}
\hline Char & Code \\
\hline Blank & 0 \\
\hline A & 1 \\
\hline B & 2 \\
\hline C & 3 \\
\hline D & 4 \\
\hline E & 5 \\
\hline F & 6 \\
\hline G & 7 \\
\hline H & 8 \\
\hline I & 9 \\
\hline J & 10 \\
\hline K & 11 \\
\hline L & 12 \\
\hline M & 13 \\
\hline N & 14 \\
\hline O & 15 \\
\hline P & 16 \\
\hline Q & 17 \\
\hline R & 18 \\
\hline S & 19 \\
\hline T & 20 \\
\hline U & 21 \\
\hline V & 22 \\
\hline W & 23 \\
\hline X & 24 \\
\hline Y & 25 \\
\hline Z & 26 \\
\hline & \\
\hline
\end{tabular}

Alphabets number assignment shown in Table 3 was used as the basis for coding to generate the morpheme dictionary. This assignment scheme made the generation of the dictionary simple and computationally inexpensive.

\subsection{MORPHEME DICTIONARY GENERATION}

\subsubsection{Morpheme coding system}

The morphemes were coded by a simple approach of adding the coded numbers for each character. The target morpheme assigned, for instance, the morpheme "ing" was coded as follows:

Step 1: assign the constituent characters in the morpheme with their respective numbers

$$
\begin{aligned}
& \mathrm{i}=9 \\
& \mathrm{n}=14 \\
& \mathrm{~g}=7
\end{aligned}
$$

Step 2: sum them up

$$
9+14+7=30
$$

From the calculation performed, the morpheme "ing" would be assigned the correspondent code representation 30. Thus, in the dictionary, the morpheme "ing" would be represented by the code 30 . All the other morphemes were coded likewise and were assigned code representations. Using the same process of coding, the morpheme dictionary was obtained as shown in Table 4.

\subsection{Demonstration of the Proposed} Algorithm for English Language Text Data The English language is used for the implementation of the proposed algorithm. The choice of English Language was its widespread; global language; most important and popular language worldwide [4]. Again, English is considered the most widely and commonest language on the Internet [16].

English sentence is selected for the illustration of the proposed approach since this is the language used in implementation.

"The display of joyfulness by miss joyce in playing computer games using a joystick is enjoyed by her friends".

The given sentence contains 19 words but the resultant morpheme count is 27 .

Algorithm

i. Read the sentence word by word

ii. Send each word to the morphemes unit one by one to be partitioned into its morphemes. For example, morphemes unit partitions the string "display" into two morphemes:

display as "dis" and "play".

joyfulness as "joy" "ful" and "ness"

miss as "mis" and "s"

joyce as "joy" and "ce"

playing as "play" and "ing"

computer as "compute" and " $r$ "

games as "game" and "s"

using as "us" and "ing" 
joystick as "joy" and "stick"

enjoyed as "en", "joy" and "ed"

her as "he" and " $r$ "

friends as "friend" and "

\subsection{Theoretical Consideration of the Proposed Algorithm}

We took the sentence under consideration morpheme-bymorpheme vis-a-vis the number of times each morpheme is repeated in the given sentence. For example, "joy" reoccurred four (4) times. This proposed algorithm proposes that, if the morpheme "joy" is encoded and represented by a token (code representation) which is less than the number of characters involved instead of the usual conventional requirements of this individual character being repeated, there could be some significant saving of storage space of a storage resource. The detailed breakdown of the sentence and the inherent character redundancies is done below:

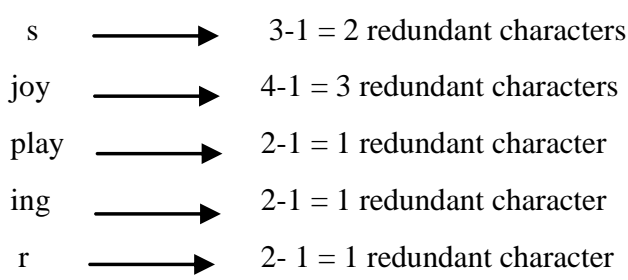

The morpheme-based technique represents the original 27 morphemes in only 19. Certainly, the actual format used for the storage of text is generally binary rather than ASCII morphemes like this, but the principle remains the same.

\subsection{Compression Performance Metrics}

According to Ida Mengyi $\mathrm{Pu}$, "the compression effect of an algorithm is measured by the amount of shrinkage of the source file in relation to the size of the compressed version" [7]. From this assertion, the following formulae are provided:

$$
\mathrm{CR}=\mathrm{Lac} / \mathrm{Lbc}
$$

where CR represents compression ratio; Lac represents the size after compression and Lbc size before compression.

$$
\begin{aligned}
& \mathrm{CR}={ }^{L a c} / \text { Lbc } \\
& \mathrm{CR}=19 / 27 \\
& \mathrm{Cf}={ }^{16 c} / \text { Lac } \\
& ={ }^{27} / /_{19}
\end{aligned}
$$

where $\mathrm{Cf}$ represents compression factor

$$
\begin{aligned}
S p & =[(\operatorname{Lbc}-\operatorname{Lac}) / L b c] * 100 \\
& =[(27-19) / 27] * 100 \\
& =29.6 \%(1 \mathrm{dp} .)
\end{aligned}
$$

where $\mathrm{Sp}$ represents saving percentage

$$
\begin{aligned}
\mathrm{Cg} & =100-(\mathrm{Lac} / \mathrm{Lbc}) * 100 \\
& =100-(19 / 27) * 100
\end{aligned}
$$

$$
=29.6 \text { (1 dp.) }
$$

where $\mathrm{Cg}$ represents compression gain.

\subsection{Decompression Component}

The decompression method is the same as the compression aspect. It uses the same components as the compression algorithm. The compressed text whose first string is a word is read since the morpheme is not modified during decompression. Coded text data is replaced by the original morpheme in the word. At the decompression, the string replaces the coded representation. The code will be the same as the one created since during compression the order of morpheme remains same during compression/decompression process. At the same time, the alphabetic text is transmitted to the output unit. If the entry text is a coded representation, then its code is searched for and replaced. The searching and replacement process is continued till the end of the file is reached and finally, the original text is produced from the compressed text.

\subsection{Implementation of the Proposed Algorithm}

The performance of the algorithm was measured using 30 text files of sizes ranging from 10 Kilobytes to 7,181 Kilobytes. The texts were selected from different sources. The data collected for the experiment were grouped into four categories: namely, small-sized files (file_size $<100$ kilobytes), middle-sized files (file_size <200 kilobytes), largesized files (file_size $<1000$ kilobytes), and very large-sized (file_size >1000 kilobytes). The summary of the categories is indicated in Table 5.

\subsection{Experimental Design and Testing Environment}

Hewlett-Packard Pentium IV of system type 32-bit operating system; processor of type Intel(R) Atom(TM) CPU

N455 of speed $1.66 \mathrm{GHz}$ machine with an installed memory (RAM) of $1.00 \mathrm{~GB}$, a Hard disk capacity of 217 gigabytes and having Microsoft Windows XP as its Operating System was used to run the various texts.

\section{RESULTS AND DISCUSSIONS}

\subsection{Data Classification}

The data collected for the experiment were grouped into four categories: namely, small-sized files (file_size $<100$ kilobytes), middle-sized files (file_size $<200$ kilobytes), largesized files (file_size $<1000$ kilobytes), and very large-sized (file_size > 1000 kilobytes). 


\subsection{Small-Sized File Category}

The ten (10) different files range from $10 \mathrm{~KB}$ to $81 \mathrm{~KB}$. The experimental results in Table 6 showed gain of storage space increased from $3.9 \%$ to $96.5 \%$. On the average, there was an overall saving percentage of $59.39 \%$ in the small-sized category.

The outcome of the experiment is summarised using graph in Figure 4.

Table 4: Morpheme dictionary

\begin{tabular}{|c|c|c|c|c|c|}
\hline Morpheme & Index & Morpheme & Index & Morpheme & Index \\
\hline $\mathrm{a}$ & 1 & ster & 62 & ings & 49 \\
\hline arch & 30 & er & 23 & ies & 33 \\
\hline be & 7 & vice & 39 & semi & 46 \\
\hline un & 35 & let & 37 & ingly & 67 \\
\hline in & 23 & ie & 14 & fully & 76 \\
\hline non & 43 & hood & 42 & ily & 46 \\
\hline dis & 32 & ship & 52 & est & 44 \\
\hline de & 9 & dom & 32 & es & 24 \\
\hline inter & 66 & ry & 43 & $\mathrm{e}$ & 5 \\
\hline mis & 41 & ing & 30 & en & 19 \\
\hline mal & 26 & ful & 39 & $\mathrm{~S}$ & 19 \\
\hline pseudo & 80 & ite & 34 & ers & 42 \\
\hline super & 79 & an & 15 & er & 23 \\
\hline out & 56 & ist & 48 & ence & 27 \\
\hline sur & 58 & ism & 41 & ences & 46 \\
\hline sub & 42 & or & 33 & ably & 40 \\
\hline over & 60 & rs & 37 & ement & 57 \\
\hline under & 62 & ant & 35 & ements & 76 \\
\hline hyper & 72 & ment & 52 & ely & 42 \\
\hline ultra & 72 & al & 13 & ations & 78 \\
\hline mini & 45 & age & 13 & ation & 59 \\
\hline $\mathrm{co}$ & 18 & ness & 57 & ance & 23 \\
\hline pan & 31 & ise & 33 & ances & 42 \\
\hline anti & 44 & en & 19 & ally & 50 \\
\hline pro & 49 & less & 55 & ors & 52 \\
\hline trans & 72 & ly & 37 & ments & 71 \\
\hline fore & 44 & like & 37 & ively & 73 \\
\hline pre & 39 & $\mathrm{y}$ & 25 & ive & 36 \\
\hline post & 70 & ish & 36 & ity & 54 \\
\hline ex & 29 & ian & 24 & ions & 57 \\
\hline re & 23 & ic & 12 & ion & 38 \\
\hline uni & 44 & ive & 36 & ward & 46 \\
\hline mono & 57 & ous & 55 & ed & 9 \\
\hline bi & 11 & able & 20 & wise & 56 \\
\hline di & 13 & wards & 65 & ure & 44 \\
\hline multi & 75 & proto & 84 & ry & 43 \\
\hline tri & 47 & poly & 68 & counter & 96 \\
\hline neo & 34 & auto & 57 & & \\
\hline
\end{tabular}


Table 5: Text categories

\begin{tabular}{|c|c|c|c|}
\hline $\begin{array}{c}\text { SSF } \\
\text { (file_size }<100 \mathrm{~KB}\end{array}$ & $\begin{array}{c}\text { MSF } \\
\text { (file_size }<200 \mathrm{~KB})\end{array}$ & $\begin{array}{c}\text { LSF } \\
(\text { file_size }<1000 \mathrm{~KB})\end{array}$ & $\begin{array}{c}\text { VLSF } \\
(\text { file_size }>1000)\end{array}$ \\
\hline 10 & 101 & 349 & 1,169 \\
\hline 11 & 104 & 438 & 1,177 \\
\hline 14 & 128 & 567 & 2,109 \\
\hline 18 & 144 & 621 & 2,123 \\
\hline 18 & 152 & 800 & 7,181 \\
\hline 37 & 152 & & \\
\hline 38 & 175 & & \\
\hline 43 & 182 & & \\
\hline 44 & 183 & & \\
\hline 81 & 199 & & \\
\hline
\end{tabular}

MSF:Middle-sized File

VLSF: Very Large-sized File
SSF:Small-sized File

LSF:Large-sized File

Table 6: Experimental result and compression gain of small-sized file category

\begin{tabular}{|l|l|c|c|c|}
\hline File \# & \multicolumn{1}{|c|}{ Category } & $\begin{array}{c}\text { Original size } \\
\text { (KB) }\end{array}$ & $\begin{array}{c}\text { Compressed size } \\
\text { (KB) }\end{array}$ & $\begin{array}{c}\text { Saving } \\
\text { percentage }\end{array}$ \\
\hline SSF 1 & Researcher mock text 1 & 10 & 0.1 & 89.1 \\
\hline SSF 2 & Curriculum & 18 & 4.6 & 70.4 \\
\hline SSF 3 & A paper on data revising dictionary & 81 & 68.8 & 15.1 \\
\hline SSF 4 & Bible text & 11 & 0.4 & 96.5 \\
\hline SSF 5 & Dr. Gordon Moore IC 1965 article & 18 & 15.9 & 11.9 \\
\hline SSF 6 & Data compression literature & 44 & 42.3 & 3.9 \\
\hline SSF 7 & Article on polytechnic education & 37 & 8.1 & 78.1 \\
\hline SSF 8 & Readme "Calgary News" & 14 & 2.4 & 83.0 \\
\hline SSF 9 & Educational committee report & 43 & 5.4 & 87.5 \\
\hline SSF10 & Project documentation Software Eng. & 38 & 17.2 & 54.8 \\
\hline
\end{tabular}

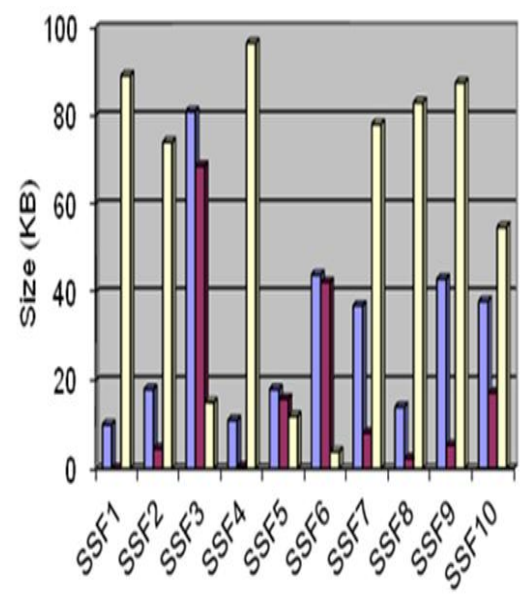

Files

\section{Figure 4: Compression gain for small-side files}

\subsection{Middle-sized Files Category}

The middle-sized file (MSF) category consists of collection of text data of sizes smaller than 200 kilobytes, (file_size $<200$ kilobytes). The ten (10) different files in this category ranged from $101 \mathrm{~KB}$ to $199 \mathrm{~KB}$. The experimental results are summarised in Table 7. The results show gains in storage resource space from $3.5 \%$ to $83.3 \%$. The average saving percentage is $34.53 \%$. The results are further graphed as shown in Figure 5.

\subsection{Large-sized Files (LSF) Category}

The experimental results of this category show saving percentages from $44.3 \%$ to $77.4 \%$ as summarised in Table 8 with average overall percentage of $63.54 \%$. The results are further indicated in Figure 6.

\subsection{Very Large-sized Files Category}

A close inspection of Table 9 suggests that better compression percentages were recorded for larger texts for the compression technique. It made gains from $18.5 \%$ to $96.4 \%$. In general, an average of $60.62 \%$ compression percentage was obtained for files whose size is larger than 1000 Kilobytes and it gradually increases as the file size gets larger as indicated in Table 9. Figure 7 establishes the graphical aspect of the very largesized file category.

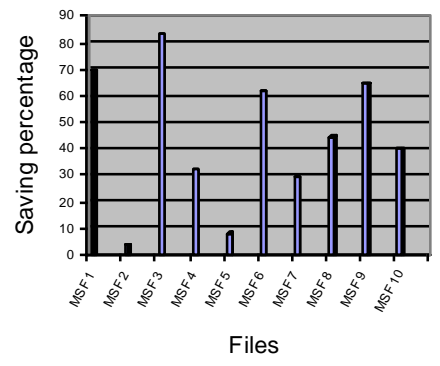

Figure 5: Compression percentage for middle-sized files 
Table 7: Experimental results of middle-sized file category

\begin{tabular}{|c|l|c|c|c|}
\hline File \# & \multicolumn{1}{|c|}{ Category } & $\begin{array}{c}\text { Original size } \\
\text { (KB) }\end{array}$ & $\begin{array}{c}\text { Compressed size } \\
\text { (KB) }\end{array}$ & $\begin{array}{c}\text { Saving } \\
\text { percentage }\end{array}$ \\
\hline MSF 1 & Student Project work & 104 & 31.5 & 69.7 \\
\hline MSF 2 & E-book "Double Your Dating" & 175 & 168.8 & 3.5 \\
\hline MSF 3 & Text collection on algorithm & 144 & 24.1 & 83.3 \\
\hline MSF 4 & Mini project in Software Engineering & 101 & 68.5 & 32.1 \\
\hline MSF 5 & Bank of Ghana 2005 annual report & 183 & 168.1 & 8.2 \\
\hline MSF 6 & Book MS. Word program & 199 & 76.4 & 61.6 \\
\hline MSF 7 & MSC Thesis & 152 & 107.5 & 29.3 \\
\hline MSF 8 & Oxford journal paper" & 128 & 71.0 & 44.5 \\
\hline MSF 9 & Skills assessment report & 152 & 54.0 & 64.5 \\
\hline MSF10 & Article on mobile telephone & 182 & 109.0 & 40.1 \\
\hline
\end{tabular}

Table 8: Experimental Results of Large-sized File Category

\begin{tabular}{|l|l|c|c|c|}
\hline File \# & \multicolumn{1}{|c|}{ Category } & $\begin{array}{c}\text { Original size } \\
\text { (KB) }\end{array}$ & $\begin{array}{c}\text { Compressed size } \\
\text { (KB) }\end{array}$ & $\begin{array}{c}\text { Saving } \\
\text { percentage }\end{array}$ \\
\hline LSF 1 & Researcher mock text 2 & 567 & 231.4 & 59.2 \\
\hline LSF 2 & UEW Thesis & 621 & 233.2 & 64.4 \\
\hline LSF 3 & Book "Getting Started with ICT & 800 & 445.3 & 44.3 \\
\hline LSF 4 & $\begin{array}{l}\text { project “Using Rhythmic Pattern to } \\
\text { improve Pupil's handwriting }\end{array}$ & 349 & 79.0 & 77.4 \\
\hline LSF 5 & $\begin{array}{l}\text { Thesis “Adoption of e-banking in } \\
\text { Ghana" }\end{array}$ & 438 & 111.9 & 74.4 \\
\hline
\end{tabular}

Table 9: Very Large-sized Files Category

\begin{tabular}{|c|l|c|c|c|}
\hline File \# & \multicolumn{1}{|c|}{ Category } & $\begin{array}{c}\text { Original size } \\
\text { (KB) }\end{array}$ & $\begin{array}{c}\text { Compressed size } \\
\text { (KB) }\end{array}$ & $\begin{array}{c}\text { Saving } \\
\text { percentage }\end{array}$ \\
\hline VLSF 1 & Researcher mock text 2 & 2,123 & 76.42 & 96.4 \\
\hline VLSF 2 & UEW Thesis & 1,117 & 682.4 & 42.4 \\
\hline VLSF 3 & Book "Getting Started with ICT & 1,169 & 953.9 & 18.5 \\
\hline VLSF 4 & $\begin{array}{l}\text { project "Using Rhythmic Pattern to } \\
\text { improve Pupil's handwriting }\end{array}$ & 7,181 & 112.2 & 98.4 .4 \\
\hline VLSF 5 & $\begin{array}{l}\text { Thesis "Adoption of e-banking in } \\
\text { Ghana" }\end{array}$ & 2,109 & $1,099.0$ & 47.8 \\
\hline
\end{tabular}

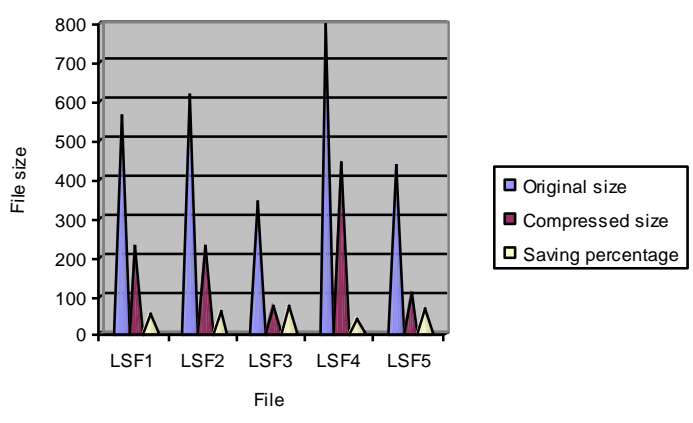

Figure 6: Compression gain in large-sized file category

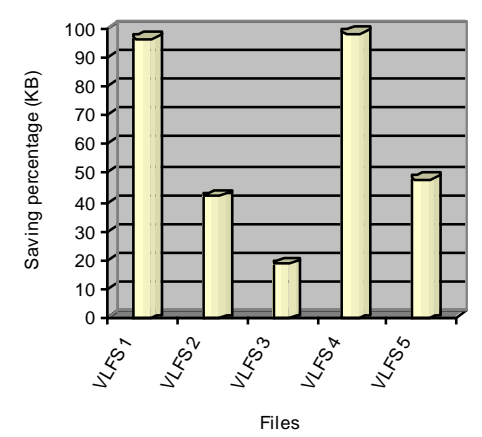

Figure 7: Compression gain in very large-sized file category 


\subsection{Comparison of Compression Percentages for the Four Categories of File Sizes}

From Figure 8, the compression percentages for the four categories of files fluctuated. SSF category recorded a highest compression gain of $96.5 \%$ and a lowest compression gain of $3.9 \%$. MSF category had a highest compression gain of $83.3 \%$ and also depreciated to a lowest percentage of $3.5 \%$. Again, LSF recorded a highest compression gain of $77.4 \%$ and a lowest compression gain of $44.3 \%$; while VLSF category had a highest gain of a storage resource space of $98.4 \%$ with a least gain in storage space of $18.5 \%$. It is important to note that saving percentages for the four categories follow similar trends depending only on the size of the source files as shown in Figure 8. This means that the content of the text does not affect the performance of the proposed morpheme-based compression technique.
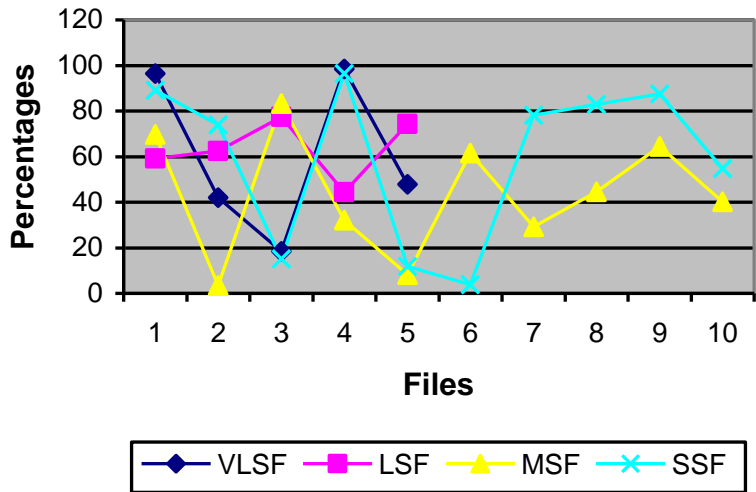

Figure 8: Compression percentages for the four categories of file sizes

\section{CONCLUSION}

Considering the analysis, it could be inferred that on the average, as the size of data increases, the performance of the proposed algorithm also improved. This could be observed among the very large-sized file (VLSF) category. VLSF 3 of size $1,169 \mathrm{~KB}$ had a saving percentage of $18.5 \%$ and VLSF $1,177 \mathrm{~KB}$ recorded $42.0 \%$. Equally, VLSF 1 of size $2,123 \mathrm{~KB}$ recorded $96.4 \%$ compression gain, while VLSF 4 of size $7,181 \mathrm{~KB}$ obtained a compression percentage of $98.4 \%$. These observations could confirm the report of IDC in 2011 that most of the digital content is not unique. They reported that nearly $75 \%$ of our digital world is a copy; only $25 \%$ is unique. Again, it was noted that saving percentages for the four categories follow similar trends depending only on the size of the source files as shown in Figure 8. This means that the content of the text does not affect the performance of the proposed morpheme-based compression technique. It was also observed that morpheme-based text compression technique was very suitable for all manner of file sizes - small, middle, large, or very large. This could be so because the proposed morpheme-based compression took advantage of the character, word and syllable methods of data compression.

\section{ACKNOWLEDGMENTS}

Authors are thankful to Dr. M. Asante, Head of Department, Computer science, Kwame Nkrumah University of Science and Technology (KNUST), Kumasi.

\section{REFERENCES}

[1] Akman, I. et'al. 2011. Lossless text compression technique using syllable based morphology. The International Arab Journal of Information Technology, Vol. 8, No. 1, January 2011.

[2] Andrew, B. 2011. Big Data. www.zdnet.com/blog/service...of...data...growing.../4750 http://www.zdnet.com/five-big-data-trendsrevolutionizing-retail-7000019510/

[3] International Dictionary of English. 2002. Morpheme is the smallest bit of language. Low Price Edition, University Press.

[4] David G. 2000. The future of English; A guide to forecasting the popularity of English Language in the 21 st century.

[5] Distributed proofreaders. 2011. Digitisation of Public Domain Books. http://www.pgdp.netg. (accessed 2011 October 20).

[6] http://www.codeguru.com/cpp/cpp/algorithms/compressi on/article.php/c5089/ (accessed 2010 August 13).

[7] Ida, M. P. 2006. Fundamental data compression. Butterworth-Heinemann Linacre House, Jordan Hill, Oxford OX2 30 Corporate Drives, Suite 400, Burlington, MA 01803.

[8] Jon, N. 2007. Digital Text Community - new forum on digitizing "ink-on-paper" texts. http://www.teleread.com /ebooks/digital-text-community-new-forum-on digitizing-ink-on paper-texts/ (accessed 2011 October 24).

[9] Lansky, J., Zemlicka, M. 2005. Text Compression: Syllables Conference: Databases, Texts, Specifications, Objects - DATESO, pp. 32-45, 2005 http://academic.research.microsoft.com/Publication/1873 500/text-compression-syllables. (Access 2011 December 14).

[10] Mark, C. 2003. An Introduction to Language. ENG 346: Aspects of the English Language Lesson 4: Morphology.Updated January 7, 2003. http://www.uncp.edu/home/canada/work/markport/langu age/aspects/spg2003/04morph.htm. (accessed 2012 April 3).

[11] Mark, N. 1989. Data compression, LZW Data Compression http://marknelson.us/1989/10/01/lzw-datacompression.

[12] Mark, N. and Jean-loup, G. 1995. The Data compression book 2nd edition, M\&T Books, Wiley, New York, NY http://staff.uob.edu.bh/files/781231507_files/The-DataCompression-Book-2nd-edition.pdf

[13] Shenfeng, C. 1996. Algorithmic Applications of data Compression Techniques. Department of Computer Science; Duke University. http://www.cs.duke.edu/ reif/ paper/chen/chen.thesis/chen.thesis.pdf.

[14] Skibi'nski, P. Grabowski, S. Z., and Deorowicz, S. 2005. Revisiting dictionary-based compression Software Practice and Experience. (accessed 2012 January 11).

[15] Social Media Informer. 2012. Data is growing and shows no signs of slowing down. http://www.socialmedia 
informer.com/data/information/statistics/ (accessed 2012 December 4).

[16] Web Technology Survey. Usage of content languages for websites.http://w3techs.com/technologies/overview/cont ent_language/all
[17] Wikipedia. 2012. Converting already published books into eBooks. en.wikipedia.org/wiki/Gutenberg (accessed 2012 May 5).

[18] Wolfram, S. 2002. A new kind of science. Notes for Chapter 10: Processes of Perception and Analysis Section: Data Compression Page 1069 http://www.wolfram_science.com/nksonline/page-1069btext?firstview=1 (accessed 2011 March 10). 